\title{
Article
}

\section{Development of an Organic Iodine Filter for Filtered Containment Venting Systems of Nuclear Power Plants}

\author{
Shinichi KAWAMURA ${ }^{1, *}$, Takeo KIMURA ${ }^{1}$, Fumitoshi WATANABE ${ }^{2}$, \\ Kazuki HIRAO ${ }^{2}$ and Tadashi NARABAYASHI ${ }^{3}$ \\ ${ }^{1}$ Nuclear Asset Management Department, Tokyo Electric Power Company Holdings, 1-1-3 Uchisaiwai-cho, Chiyoda-ku, \\ Tokyo 100-8560, Japan \\ ${ }^{2}$ R\&D Department, TEPCO Research Institute, Tokyo Electric Power Company Holdings, 4-1 Egasaki-cho, Tsurumi-ku, \\ Yokohama 230-8510, Japan \\ ${ }^{3}$ Division of Energy and Environmental Systems, Graduate School of Engineering, Hokkaido University, Kita-13, Nishi-8, Kita-ku, \\ Sapporo 060-8628, Japan
}

\begin{abstract}
A design for an organic iodine filter was developed for filtered containment venting systems of nuclear power plants. After the Fukushima Daiichi Nuclear Accident, filtered containment venting systems were developed and installed at nuclear power plants in Japan employing aerosol filters, which are typically combinations of alkaline water scrubbers and metal fiber filters. Using silver zeolite, the newly designed filter absorbs organic iodine, which cannot be captured with alkaline water scrubbers and metal fiber filters. Methyl iodide absorption performance tests were conducted with various gas velocities and compositions, which covered the operating conditions of filtered containment venting systems. The test results demonstrated that the decontamination factors of the silver zeolite were over 50 if an appropriate gas contact time was ensured, even though steam condensation and the existence of hydrogen during vent startup had negative effects on the absorption performance. It was also revealed from the tests that intermittent venting might dampen the silver zeolite and reduce its absorption performance. Flow control of the vent gas was found to be an effective countermeasure to maintain the performance even under such conditions. Filter unit tests and numerical analyses of the gas flow within the filter vessel confirmed that the gas contact time was uniform in the filter and appropriate for achieving a decontamination factor of 50 .
\end{abstract}

KEYWORDS: accident, filtered containment venting system, nuclear power plant, primary containment vessel, iodine, decontamination factor, performance, experiment

\section{Introduction}

In the accident at the Fukushima Daiichi Nuclear Power Plant, the reactor core melted down due to cooling failure resulting from the damage caused by the tsunami after the shutdown of the reactor. Part of the primary containment vessel (hereinafter referred to as "containment

* Corresponding author, E-mail: shinichi.kawamura@tepco.co.jp

DOI : 10.15669/fukushimainsights. Vol.4.509

(C) 2021 Atomic Energy Society of Japan. All rights reserved.

Originally published in Transactions of the Atomic Energy Society of Japan (ISSN 1347-2879), Vol. 15, No. 4, p.192-209

(2016) in Japanese. (Japanese version accepted: June 1, 2016) 
vessel") was damaged, and a large amount of radioactive material escaped into the environment. Based on the lessons learned from this accident, various countermeasures are being taken from the perspective of defense in depth. A part of this effort includes the development of a filtered containment venting system (hereinafter referred to as an FCVS) ${ }^{1-4)}$ to protect the containment vessel from over-pressure damage as well as to considerably reduce the emission of radioactive substances during severe accidents.

An FCVS consists of a piping system used to exhaust (vent) gas from the gas-phase of the containment vessel to a high place, and a filter system to collect radioactive substances in the gas and suppress their release into the atmosphere. The main radioactive substances released into the atmosphere from the accident at the Fukushima Daiichi Nuclear Power Plant were noble gases, cesium and iodine ${ }^{5}$. With respect to noble gases, we plan to suppress the rise in pressure and temperature in the containment vessel by spraying the vessel, or some similar activity, to delay the time when venting becomes necessary, and to attenuate the noble gases. This process can be expected to remove cesium and iodine with the filter system. Previous studies have involved the capture of cesium and inorganic iodine from the venting gas with a decontamination factor (hereinafter referred as DF) of 1,000 or more by an FCVS filter device, which is a combination of alkaline water scrubbers and metal filters ${ }^{1,3,4,6)}$. However, this device cannot effectively capture organic iodine.

Although filters that capture iodine with silver zeolite have demonstrated significant efficiency at fuel reprocessing plants, so a worthwhile capture efficiency of organic iodine might be expected, the following information suggests that such a filter would be insufficient when part of an FCVS system. Although zeolite has high hygroscopicity, iodine adsorption performance will decrease due to the absorption of moisture. However, the moisture in the FCVS, which is required for the operation of the system during a loss of AC power at the time of an accident, cannot be removed. Also, it is necessary for the FCVS to treat hydrogen-containing gas, but the hydrogen may reduce the silver and thus impair the iodine removal. Furthermore, since the pressure difference between the containment vessel and the atmosphere allows gas to flow without the use of dynamic devices such as fans, the gas flow rate changes greatly during operation. Relevant knowledge is required to deal with these issues before an organic iodine filter with silver zeolite can be developed for FCVS. There have been reports by Ishii et al. ${ }^{7}$ and Narabayashi et al. ${ }^{8)}$ on the application of silver zeolite to FCVS, but the performance characteristics in an actual device under the assumed conditions has not been presented. Kobayashi et al. ${ }^{9)}$ has reported on the adsorption performance characteristics of silver zeolite under various flow conditions, but it is necessary to understand the performance characteristics for the organic iodine concentration at a gas temperature much closer to the usage conditions of the actual device, especially during the initial venting stage when the conditions are more severe. There has been no record of development or commercialization of organic iodine filters for FCVS in Japan, including these studies.

Meanwhile, the DF requirement for inorganic iodine is 10 or greater for the seven nuclear power plants in Germany. In this case, iodine filters with molecular sieves have been installed, which also exhibit a certain organic iodine removal capability, but the performance characteristics of the filters are not clear. A filter with a DF requirement value of $10^{10)}$ was introduced to the Krško NPP in Slovenia in 2013 as a filter with a DF specification for organic iodine, but there is no published document regarding its performance characteristics.

Therefore, in this study, we consider the process of containment vessel venting subsequent to a typical severe accident at a BWR plant that involves core damage, a loss of coolant, a power station blackout, and a loss of all emergency core cooling systems due to a large break accident at an ABWR. In this scenario, we have conducted experimental studies on the performance 
characteristics of organic iodine removal using silver zeolite, and developed a filter with an organic iodine DF that exceeds 50, using silver zeolite as an absorbent. This DF target value was set at the time of development so as to be equal to or greater than the required value in Europe, as described above. The organic iodine filter developed is being introduced to the unit 6 \& 7 reactors at the Kashiwazaki Kariwa Nuclear Power Plant.

Disclosure of the performance characteristics of the absorbent is useful not only for this development but also for further performance improvement in the future. Also, it is important to conduct an investigation into the performance characteristics of the filter to determine the effectiveness of the FCVS, and this study provides a discussion from this point of view.

\section{Design of an Organic Iodine Filter for an FCVS}

\section{Overview of the Organic Iodine Filter}

Silver zeolite (Manufacturer: RASA Industries, LTD. model: AgX, particle size: 0.85 to $2.00 \mathrm{~mm}$, silver supported ratio: about $41 \mathrm{wt} \%$ ), which is used as the absorbent in the organic iodine filter, has $13 \mathrm{X}$ crystalline zeolite as its basic skeleton. In silver zeolite, the sodium ions in the skeleton of the aluminosilicate are exchanged for silver ions, and iodine is captured by chemically reacting with the silver. The silver zeolite used in this filter is shown in Figure 1.

In the crystal structure of zeolite, numerous pores, which affect adsorption performance, are formed by heating and removal of crystal water. Most of the venting gas from the containment vessel is water vapor, but when the pores come into contact with steam, water molecules are absorbed in the pores and the iodine adsorption performance declines. Thus, a design that can provide the proper temperature superheated steam at the filter inlet and verify performance based on these steam conditions is necessary.

The schematic diagram of the organic iodine filter is shown in Figure 2. The silver zeolite fills the space between the inner cylinder and the outer cylinder of a double-cylinder adsorption tower called a candle-type filter unit, and 19 candle-type filter units are installed in one filter vessel.

Figure 3 shows the basic system configuration of the filtered containment venting system with iodine filters as it is installed at the unit $6 \& 7$ reactors of the Kashiwazaki Kariwa Nuclear Power Plant. (ABWR type, electric output is $1356 \mathrm{MWe}$ each). Two organic iodine filters are installed in parallel downstream of the FCVS filter device. These filters remove particulate matter and inorganic iodine with a DF of 1,000 or greater. An FCVS is a facility used in severe

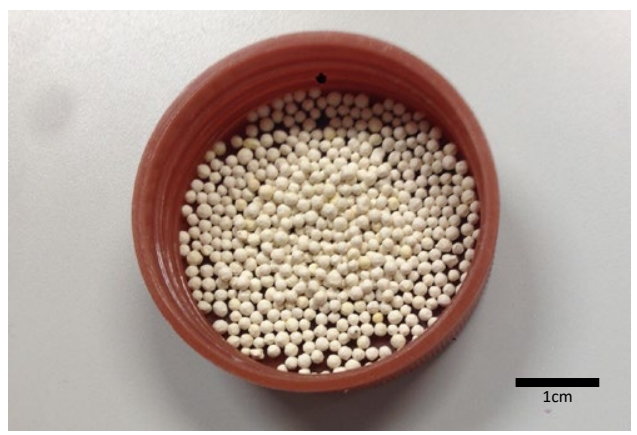

Figure 1 Silver zeolite for the organic iodine filter 


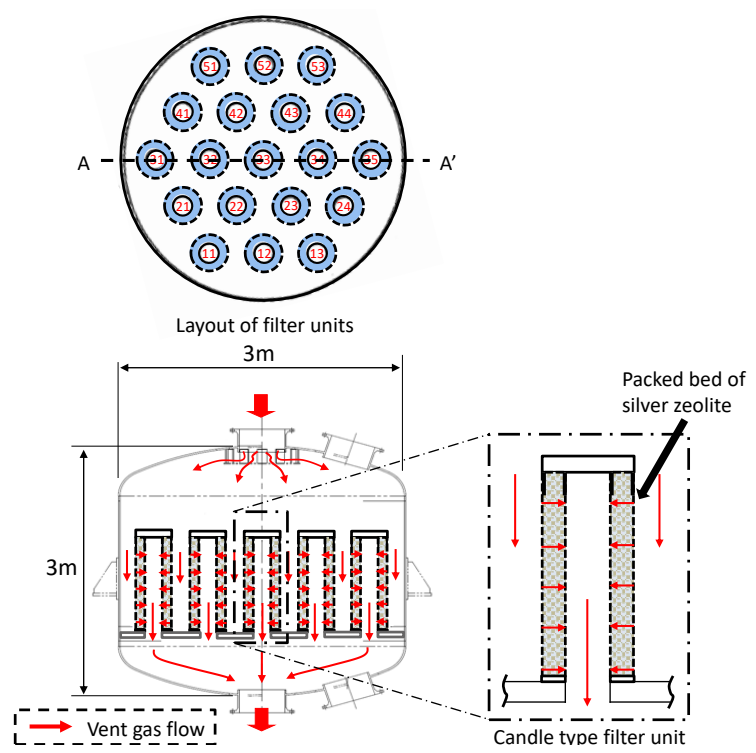

Figure 2 Schematic diagram of the organic iodine filter. Nineteen candle-type filter units, for which identification numbers are written in this figure, are installed in a filter vessel.

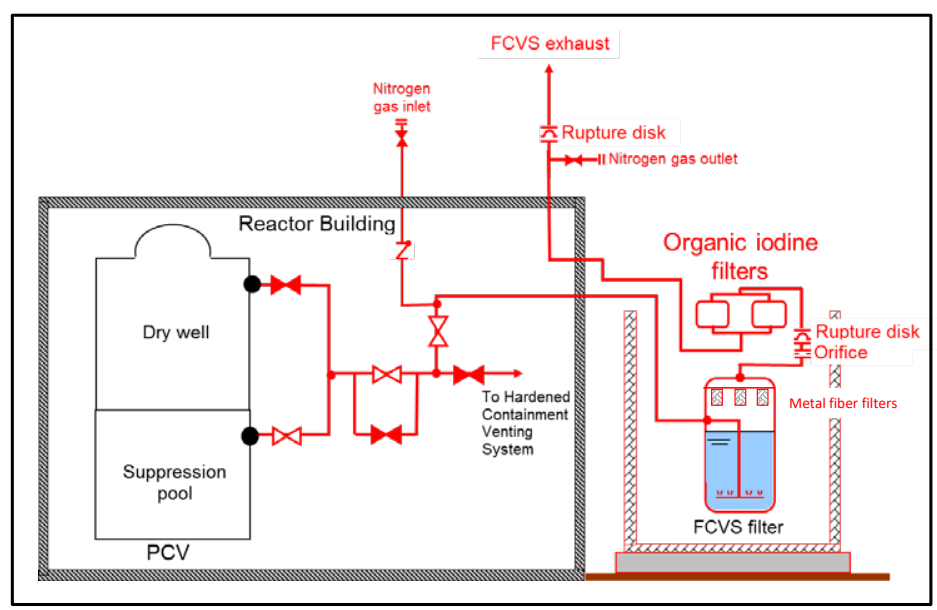

Figure 3 Basic system configuration of the filtered containment venting system with iodine filters

accidents, and it is necessary to demonstrate the required performance by manually opening the valve, as would be required in the event of loss of all AC power. Also, since a constant flow rate control cannot be achieved, the flow rate and temperature of the system change greatly during operation. And because it is necessary to prevent the performance decline of silver zeolite when it comes into contact with steam, an orifice is provided in the upstream piping of the organic iodine filter to produce an adiabatic expansion and an appropriate difference between the gas temperature and dew point, since electric heaters cannot be used. A metal filter, which acts as a demister, is installed in the FCVS, installed upstream of the organic iodine filter, and is 
designed to prevent droplets from accompanying the gas that comes from the FCVS.

A pressure release plate operating at a pressure differential of $100 \mathrm{kPa}$ is provided downstream of the organic iodine filter. With this pressure release plate as the boundary, the upstream side, including the containment vessel, will contain nitrogen gas during standby. This will prevent a high concentration of hydrogen from coming into contact with oxygen and burning in the piping, because of the steam condensed in the cold piping in the initial venting stage.

A pressure release plate operating at a differential pressure of $100 \mathrm{kPa}$ is also provided between the organic iodine filter and the FCVS filter device; because silver zeolite adsorption performance will deteriorate when it dampens, it is kept in a dry state during standby.

\section{Design Specifications of the Organic Iodine Filter}

Table 1 shows the design specifications for the organic iodine filter in the above-described system configuration.

The temperature and pressure conditions in the design of the organic iodine filter are determined from the conditions of the initial venting through the FCVS. The containment vessel is made to be able to maintain confinement at a pressure of at least twice the maximum working pressure (hereinafter $2 \mathrm{Pd}: 620 \mathrm{kPa}$ [gauge] in the case of ABWR) and $200^{\circ} \mathrm{C}^{1)}$, and venting starts up without exceeding this condition. In the route from the containment vessel to the organic iodine filter, there are pressure loss elements, such as the piping, valves, and the FCVS filter device. Therefore, even if the pressure in the containment vessel is $2 \mathrm{Pd}$, the pressure in the organic iodine filter section is lower. Therefore, the pressure loss of the FCVS system was calculated, and the maximum tolerated working pressure was set for the organic iodine filter so that it will exceed the maximum pressure that is actually generated in the organic iodine filter section. Specifically, the piping of the FCVS system can be divided into sections. The venting gas velocity in the calculation section is calculated by using the venting gas concentration calculated from the pressure and the temperature of the upstream section in sequential order, starting from the containment vessel. The local pressure losses are evaluated based on the venting gas velocity and the pressure loss coefficient (derived from the Mechanical Engineering Handbook ${ }^{11)}$, the equipment specifications, and the filter unit test results described later) of the piping (piping length / elbow / tee), valves, FCVS filter device, and organic iodine filter installed in the section under calculation, then the total pressure loss in that section is evaluated by summing all the local pressure losses. The pressure distribution of the entire FCVS system and the pressure in the organic iodine filter section are calculated by evaluating the pressure loss from the containment vessel to the exhaust outlet. Here, as a condition for the generation of the maximum pressure in the organic iodine filter, the containment vessel pressure is $2 \mathrm{Pd}$, and all

Table 1 Design specifications of the organic iodine filter for an ABWR plant

\begin{tabular}{|c|c|}
\hline & Design conditions \\
\hline Maximum design pressure ( $\mathrm{kPa}$ [gage]) & 250 \\
\hline Maximum design temperature $\left({ }^{\circ} \mathrm{C}\right)$ & 200 \\
\hline $\begin{array}{l}\text { Maximum design gas flow rate as } 100 \% \\
\text { steam condition }(\mathrm{kg} / \mathrm{s})\end{array}$ & 31.6 \\
\hline Decontamination factor & 50 \\
\hline $\begin{array}{l}\text { Maximum load of organic iodine } \\
\qquad\left(\mathrm{kg} \text { as } \mathrm{CH}_{3} \mathrm{I}\right)\end{array}$ & 1.3 \\
\hline $\begin{array}{l}\text { Maximum volume concentration of or- } \\
\text { ganic iodine (vol ppm) }\end{array}$ & 40 \\
\hline
\end{tabular}


the valves in the flow path of the venting gas are fully opened, so the pressure loss of the FCVS system can be evaluated. As a result, since the pressure in the organic iodine filter section was about $200 \mathrm{kPa}$ [gauge], the maximum working pressure in the design specification of the organic iodine filter was set to $250 \mathrm{kPa}$ [gauge] so as to exceed the above value. Also, the maximum operating temperature was $200^{\circ} \mathrm{C}$, corresponding to the condition of the containment vessel.

All of the iodine in the nuclear reactor is released to the containment vessel at the time of a severe accident. Assuming that $4 \%$ reacts with organic matter in the containment vessel to become organic iodine, it will mass about $1.3 \mathrm{~kg}$ if converted to methyl iodide, according to the Regulatory Guide $1.1951^{12)}$ of the U.S. Nuclear Regulatory Commission. According to Soffer et al. ${ }^{13)}$ and Beahm et al. ${ }^{14)}$, when maintaining the water in the containment vessel in an alkaline condition, organic iodine is suppressed to $0.15 \%$ or less of the total iodine released from the reactor primary system at the time of an accident. Since the development of a $\mathrm{pH}$ control system is in progress ${ }^{1)}$, we decided not to estimate its effect here because the organic iodine filter is expected to perform its function independently. Since the distribution of organic iodine in the containment vessel is quite uncertain, and the organic iodine concentration is conservatively estimated to be of a higher level, assuming that the full amount of the organic iodine is in the gasphase in the containment vessel suppression chamber, which is connected to the FCVS piping, the volume concentration of organic iodine is about $40 \mathrm{vol}$. ppm immediately before venting.

The flow rate and gas composition of the venting gas flowing into the organic iodine filter change after the start of venting. Considering the typical case of a severe accident involving core damage, accident analysis was conducted with MAAP code for the scenario in which a loss of coolant, a station blackout, and a loss of function of the entire emergency core cooling system occurred due to large break accident. In this analysis, the condition of the venting gas flowing into the organic iodine filter was calculated, and the results are shown in Table 2, with the results considered to be within the operating range of the organic iodine filter. The contact time is the time the gas spends passing through the silver-zeolite-packed bed, and is obtained from the following equation as the reciprocal of the space velocity SV.

$$
1 / S V=V_{A g X} / Q
$$

where, $\mathrm{V}_{\mathrm{Agx}}$ is the volume of the silver-zeolite-packed bed, and $\mathrm{Q}$ is the flow rate of the gas passing through the packed bed.

The nitrogen charged in the containment vessel at the beginning and the hydrogen accumulated after the accident account for a high proportion of the venting gas, and water vapor accounts for nearly $100 \%$ after the discharge of the venting gas. Hydrogen will reduce silver ion, which may lower the iodine adsorption performance, so it is necessary to confirm this effect by test. Also, apart from these main effects, sulfur originating in vulcanized electric cable coating material may inhibit the bonding of silver and iodine. If hydrogen sulfide is generated and reacts chemically with silver, it may inhibit the chemical reaction between iodine and silver,

Table 2 Gas conditions in the packed bed of silver zeolite for an ABWR plant

\begin{tabular}{lccc}
\hline & Vent startup & $\begin{array}{c}\text { One week after } \\
\text { continuous venting }\end{array}$ & $\begin{array}{c}\text { One month after } \\
\text { continuous venting }\end{array}$ \\
\hline Volumetric flow rate $\left(\mathrm{m}^{3} / \mathrm{s}\right)$ & 16.1 & 6.65 & 3.83 \\
Contact time $(\mathrm{s})$ & 0.222 & 0.539 & 0.934 \\
Difference between gas temperature and dew point $(\mathrm{K})$ & 82.3 & 8.6 & 7.3 \\
& Steam $10 \%$ & Steam $100 \%$ & Steam $100 \%$ \\
Gas composition other than organic iodide & Hydrogen $30 \%$ & & \\
& Nitrogen $60 \%$ & & \\
\hline
\end{tabular}


and if sulfur dioxide is generated, it may inhibit the reaction thereof by physically absorbing to zeolite. However, by keeping the scrubber water alkaline in the FCVS filter device, provided upstream of the organic iodine filter, the scrubber water will pass through these substances even if they are generated in the containment vessel. Thus it was judged unnecessary to consider their effects on the condition of the organic iodine filter.

\section{Performance Verification Test of the Organic Iodine Filter}

\section{Organic Iodine Adsorption Test}

\section{(1) Outline of the test facility}

The organic iodine removal performance of silver zeolite was confirmed by tests. Figure 4 outlines the test facility. Methyl iodide was used to represent organic iodine in the test. Since methyl iodide is highly volatile, it is thought to be the main iodine released in gaseous form at the time of an accident, and because it is small and difficult to capture, considering it as a representative gas is a conservative measure. It is also employed in the inspection of the performance of activated carbon in emergency gas treatment systems at nuclear power plants.

The gas from the methyl iodide gas generator is mixed with the steam from the boiler and introduced into a test column filled with silver zeolite. A gas injection port was provided in the pipe upstream of the test column, so that venting gas components other than water vapor, such as hydrogen and nitrogen, could be injected as needed to adjust the gas composition.

In designing a test column to be filled with silver zeolite, consideration was taken to simulate the conditions in the actual device with regard to advective diffusion, when the gas passes through the packed bed. It is expected that in the actual candle-type filter unit, the gas flows from the outside to the inside, as shown in Figure 2, because of the pressure difference inside and outside the packed bed. However, with the z-axis as the one-dimension flow direction, the equation

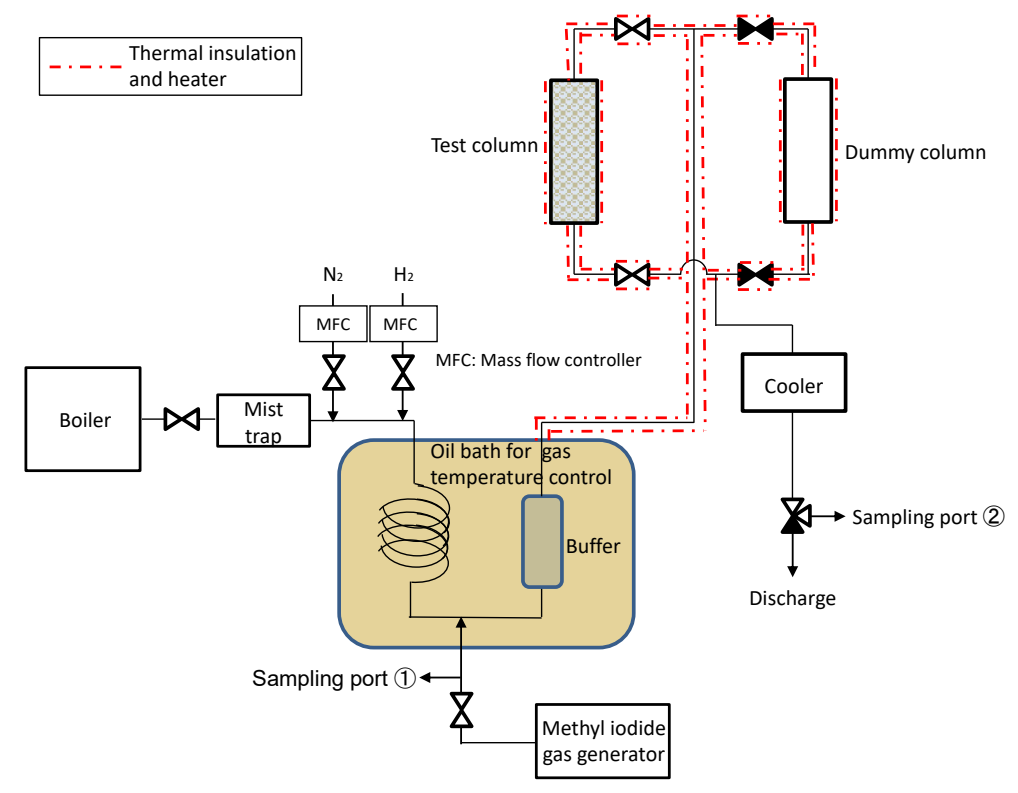

Figure 4 The test facility for methyl iodide adsorption performance of the silver zeolite 
of the advective diffusion associated with the reaction is expressed in the steady state as follows:

$$
\mathrm{u} \frac{\mathrm{dc}}{\mathrm{dz}}=D_{z} \frac{d^{2} c}{d z^{2}}-k c
$$

where, $\mathrm{c}$ is the concentration of methyl iodide, $\mathrm{u}$ is the gas velocity, $\mathrm{D}_{\mathrm{z}}$ is the mixed diffusion coefficient in the $\mathrm{z}$-direction, and $\mathrm{k}$ is the adsorption reaction speed constant of silver zeolite. Incidentally, this $\mathrm{k}$ is an overall reaction speed constant, which includes not only the chemical reaction but also factors such as the shape of silver zeolite, diffusion in silver zeolite, and the quantity of silver ions.

From this equation, we find that when filling the test column with the same silver zeolite and with the same packing as that of the actual device, basically simulating the conditions for reaction and mixing diffusion, it is necessary to adjust the distance in the flow direction, that is, the thickness of the packed bed with respect to the flow direction, as well as the gas velocity, in accordance with the actual device. Specifically, within the range that the steam production of the boiler can be adjusted, the column inner diameter is determined to ensure that the velocity in the test column can simulate the operation range of the actual device, and the packed-bed thickness (the height of the test column in Figure 4 of the test column) is set to be the same size as that of the candle-type filter unit of the actual device (the inside and outside diameter difference of the candle type filter unit of the double cylindrical structure shown in Figure 2). The influence of the gas temperature and pressure will be checked by tests.

The test column designed in this way simulates the advective diffusion in the flow direction, but the dimension in the direction orthogonal to the flow (the height of the packed bed of the candle-type filter unit in the actual device, the diameter of the test column in the test) is different, and the influence of the difference is considered as follows. First, the interior of the packed bed is filled with zeolite particles of small diameter, and it is thought that the velocity of the gas flow passing through the packed bed due to the rectification effect does not cause a large difference for most of the positions in the direction perpendicular to the flow. This will be confirmed by the filter unit test described later. However, it is thought that in such packing materials, the flow velocity increases in the vicinity of the wall in the flow paths, causing the appearance of local regions where the contact time is short and adsorption performance tends to be lower. Walls exist at the upper and lower ends of the packed portion in the candle-type filter unit of the actual device, and the inner surface of the test column is a wall, but as shown in Figure 2 and Figure 4, the wall area with respect to the packed volume is small in the actual candle-type filter unit, and the effect of the wall is considered to be smaller than that in the test column. Therefore, the adsorption performance confirmed by the test column is more conservative than the actual device. It is, therefore, considered possible to conservatively estimate the adsorption capacity in an actual device by multiplying the mass ratio of silver zeolite in both the actual device and test column by the adsorption capacity to be confirmed by the tests.

The concentration of methyl iodide supplied to the test facility was confirmed by taking a sample from sampling port 1 and analyzing it with a gas chromatograph (GC-FID: Shimadzu Corporation GC-14B, lower limit of detection concentration is 2.3 vol. ppm). On the other hand, the gas passing through the test column was diluted with nitrogen, passed through the cooling trap and was collected from sampling port 2, undergoing analysis by the GC-FID with condensed water, as samples. The outlet concentration was calculated based on this analysis value. The steam flow rate was calculated from the weight of the condensed water. 
Table 3 Test cases for methyl iodide adsorption by silver zeolite, simulating steady vent conditions

\begin{tabular}{|c|c|c|c|c|}
\hline Test number & $\mathrm{A}-1$ & $\mathrm{~A}-2$ & $\mathrm{~A}-3$ & $\mathrm{~A}-4$ \\
\hline Contact time $(\mathrm{s})$ & 0.121 & 0.119 & 0.151 & 0.134 \\
\hline Methyl iodide concentration (vol ppm) & 55 & 116 & 48 & 57 \\
\hline Difference between gas temperature and dew point & 9.1 & 10.6 & 8.5 & 12.5 \\
\hline Gas pressure $(\mathrm{kPa}[$ gage $])$ & 8.1 & 8.4 & 5.6 & 250.4 \\
\hline Gas composition other than methyl iodide & Steam $100 \%$ & Steam $100 \%$ & Steam $100 \%$ & Steam $100 \%$ \\
\hline Temperature of silver zeolite before testing & $\begin{array}{l}\text { Preheated to the } \\
\text { gas temperature }\end{array}$ & $\begin{array}{l}\text { Preheated to the } \\
\text { gas temperature }\end{array}$ & $\begin{array}{l}\text { Preheated to the } \\
\text { gas temperature }\end{array}$ & $\begin{array}{l}\text { Preheated to the } \\
\text { gas temperature }\end{array}$ \\
\hline $\begin{array}{l}\text { Absorbed methyl iodide before DF becomes less than } \\
50(\mathrm{mg})\end{array}$ & 1,637 & 1,644 & 2,431 & 1,985 \\
\hline Ratio of silver reacted with iodide (\%) & 6.1 & 6.1 & 9.0 & 7.4 \\
\hline $\begin{array}{l}\text { Evaluated allowable load of methyl iodide on two or- } \\
\text { ganic iodine filters for a plant (kg) }\end{array}$ & 131.0 & 131.5 & 194.5 & 158.6 \\
\hline
\end{tabular}

DF : Decontamination Factor.

\section{(2) Confirmation of basic performance}

To confirm the basic performance of organic iodine removal by silver zeolite, a test was conducted to simulate the steady venting state, excluding the initial venting. The test conditions are shown in Table 3.

With respect to the conditions shown in Table 2, in the design of the actual device, as discussed later in III-2-(2), considering the variations in the flow velocity distribution in the filter, it is necessary to ensure the performance with a contact time of $0.188 \mathrm{~s}$ or longer. The contact time in this test was set between about $0.12 \mathrm{~s}$ and $0.15 \mathrm{~s}$, a conservative shorter time condition, under which the steam flow rate was adjusted. The influence of gas flow velocity can be determined by comparing test No. A-1 with No. A-3. In test A-3, the gas flow velocity was slow, which resulted in a longer contact time. However, it was considered when setting the difference between the gas temperature and the dew point that the steam superheat temperature in the orifice decreases as the flow velocity decreases.

The concentration of methyl iodide was set to be about 50 vol. ppm, compared to 40 vol. $\mathrm{ppm}$ - the maximum value assumed for the actual device, as shown in Table 1. In test A-2, the concentration was increased to 116 vol. ppm, about twice as high. By comparing test A-1 with test A-2, it is possible to ascertain the influence of the concentration on adsorption performance.

Test A-4 used temperature and pressure settings close to the initial venting of the actual device, corresponding to a test condition assumed immediately after vent startup, in which the containment vessel pressure is $2 \mathrm{Pd}$ in the actual device. Hydrogen and nitrogen account for a high proportion of the venting gas composition at the beginning as shown in Table 2. But they were discharged promptly, and the water vapor remaining may account for $100 \%$. By comparing test A-1 with test A-4, the influence of the temperature and pressure can be determined.

Also, in the venting steady state, the silver zeolite has the same temperature as the venting gas, and it is not considered to be moist because the superheated steam is aerated. Therefore, in the test, the silver zeolite was in a dry state before the gas entered and was preheated with a heater outside of the test column so as to be at the same temperature as the venting gas; only then was the gas allowed to flow in.

Figures 5 to $\mathbf{8}$ show the changes in the inlet concentration, outlet concentration, and methyl iodide removal rate from the start of the test under each condition. The outlet concentration continues to be below the detection limit for a period after the start of the test but eventually begins to increase, and the methyl iodide removal rate also decreases.

In Table 3, the time during which DF maintains the design target of 50 or greater under each test condition, the fraction of silver, which absorbs iodine during this time, and the calculated 


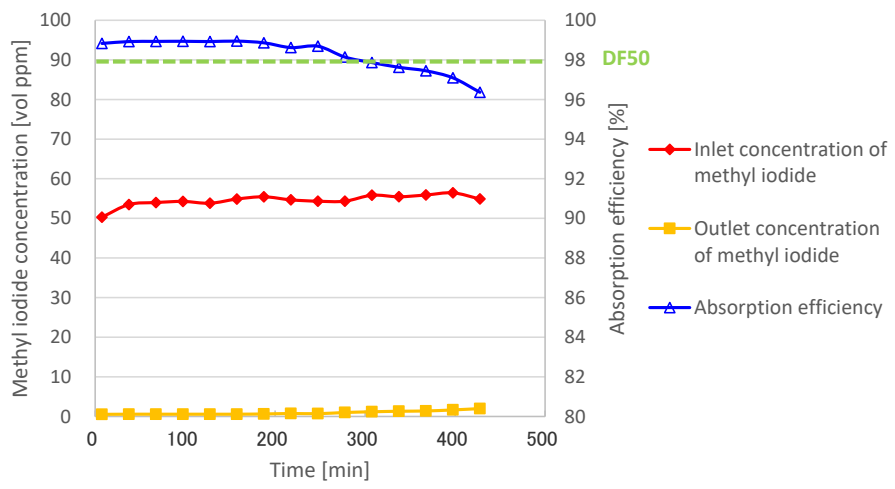

Figure 5 Results of methyl iodide adsorption performance test A-1

Test conditions are listed in Table 3 as test number A-1.

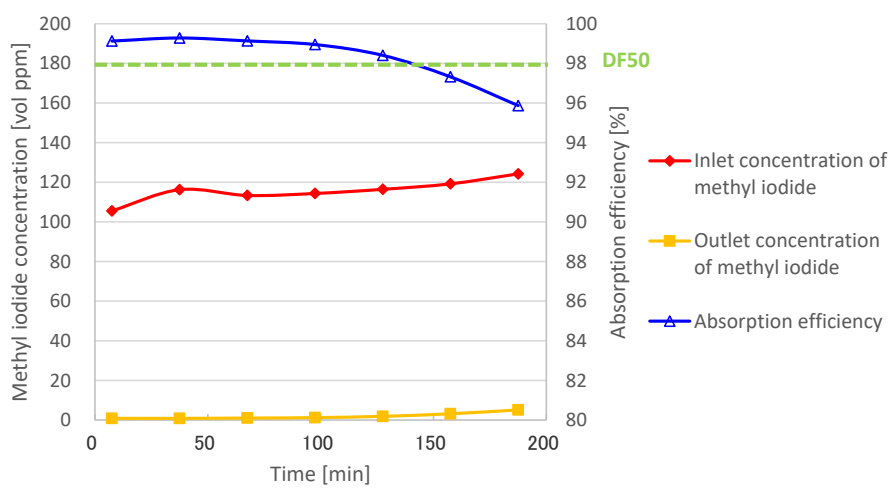

Figure 6 Results of methyl iodide adsorption performance test A-2

Test conditions are listed in Table 3 as test number A-2.

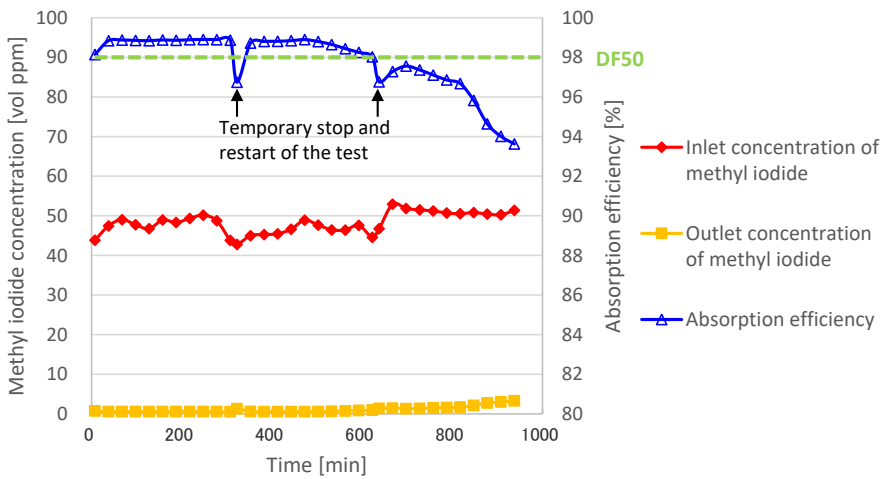

Figure 7 Results of methyl iodide adsorption performance test A-3

Test conditions are listed in Table 3 as test number A-3. Performance drops were observed when the test was suspended and resumed because residual methyl iodide was measured at the outlet. This was not considered as relevant to the performance of silver zeolite. 


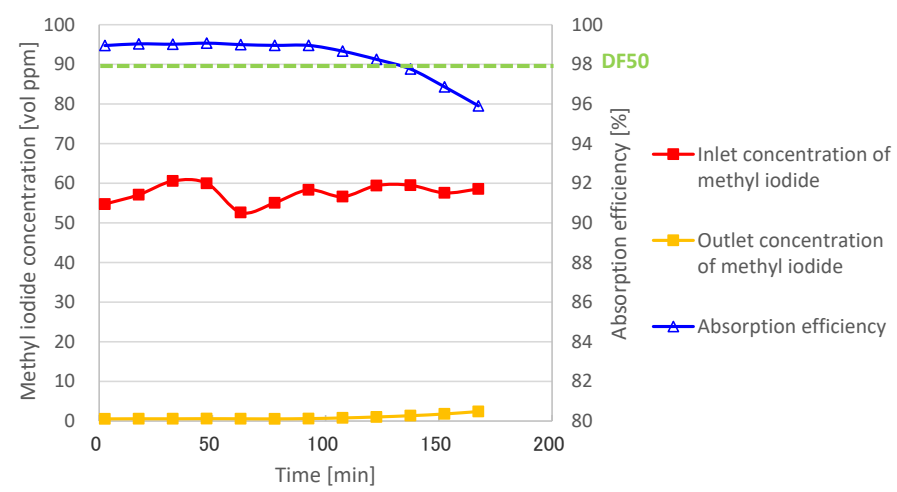

Figure 8 Results of methyl iodide absorption performance test A-4 Test conditions are listed in Table 3 as test number A-4.

result of the allowable adsorption load of the organic iodine filter are also described. The allowable adsorption load of the organic iodine filter is the total mass (as shown in Figure 3, since two filters are installed in parallel, the total value) of organic iodine (methyl iodide) absorbed by the organic iodine filters of the actual device during the period when the DF is maintained at 50 or greater, which is calculated by the following equation

$$
\mathrm{A}=\int_{0}^{T_{50}} S I\left(1-\frac{1}{D F}\right) d t \cdot A g X_{r} / A g X_{t}
$$

where $\mathrm{A}$ is the allowable adsorption load of the organic iodine filter, SI is the mass of methyl iodide supplied to the test column per unit time, $\mathrm{DF}$ is the decontamination factor, $\mathrm{AgX}_{\mathrm{t}}$ is the total mass of silver zeolite packed in the two iodine filters, $\mathrm{AgX} \mathrm{X}_{\mathrm{t}}$ is the total mass of silver zeolite packed in the test column, and $\mathrm{T}_{50}$ is the time from the start of the test until the DF becomes less than 50 .

If the allowable adsorption load of this organic iodine filter exceeds $1.3 \mathrm{~kg}$, which is the amount of organic iodine generated in the containment vessel discussed in section II-2, the total amount of organic iodine can be treated with a DF of 50 or greater. As shown in Table 3, all four test conditions satisfied this requirement, and it was confirmed that the silver zeolite has sufficient organic iodine adsorption capacity in steady state venting.

As shown in Table 3,10\% or less of the silver ions in the silver zeolite contributed to the adsorption of iodine. Methyl iodide is believed to diffuse from the surface into the interior of the silver zeolite in an accompanying reaction. Here, considering the case with high reaction speed and slow diffusion, silver ions near the surface of the zeolite particles contribute to the reaction, but silver ions deep inside the particles do not contribute to the reaction. With this mechanism, it is conceivable that silver ions contributing to the adsorption were only a portion of the total amount.

On the other hand, comparing the individual test cases with each other, the influence of the organic iodine concentration can be obtained from the comparison between Figure 5 and Figure 6. That is, in the case in Figure 6, where the concentration is about twice that of the case in Figure 5, the removal rate begins to decline at an earlier stage, and the time for which the DF can be maintained at 50 or greater is reduced by almost half. However, the fractions of silver contributing to the reaction under both test conditions are equal, and the calculated value of the allowable adsorption load of the organic iodine filter is also equivalent.

Comparison of Figures 5 and 7 shows that the removal rate begins to decline at an earlier 


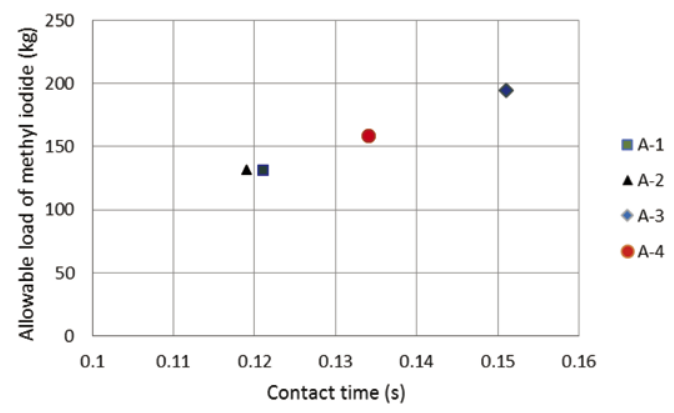

Figure 9 Relationship between contact time and allowable load of methyl iodide on two organic iodine filters for a plant

The conditions of test cases A-1 to A-4 are listed in Table 3.

stage for a shorter contact time, and the sensitivity of the contact time to the removal rate is high.

The relationship between the contact time of each test case and the allowable adsorption load obtained from equation (3) is shown in Figure 9. The amount of methyl iodide that can be absorbed while maintaining a DF of 50 or greater, including the case of changing the test temperature and pressure conditions (Test No. A-4 shown in Table 3, Figure 8), will increase with a longer contact time.

These tendencies were discussed as follows. It is considered that the flow in the packed bed is in an intermediate state of a plug flow and perfect mixing, depending on the effect of mixing diffusion. In the case of plug flow, the equation for advective diffusion in equation (2) is expressed by equation (4) since $\mathrm{D}_{\mathrm{z}}=0$, and the concentration is obtained by equation (5) by integrating equation (4)

$$
\begin{aligned}
& \mathrm{u} \frac{\mathrm{dc}}{\mathrm{dz}}=-k c \\
& \mathrm{c}=c_{0} \exp (-k z / u)
\end{aligned}
$$

where $c_{\mathrm{o}}$ is the concentration at the inlet of the packed bed. Here, when the contact time until the gas arrives at an arbitrary position $\mathrm{z}$ is set to be $\mathrm{t}$, since $\mathrm{t}=\mathrm{z} / \mathrm{u}$, the concentration, which is made non-dimensional by the inlet concentration of the packed bed, can be expressed by equation (6).

$$
c / c_{0}=\exp (-k t)
$$

The image of the non-dimensional concentration and the contact time expressed by Eq. (6) is indicated by the solid line in Figure 10. The non-dimensional concentration must be 0.02 or less to achieve a DF of 50 or greater. As shown in the figure, when the contact time is longer than the contact time limit $\mathrm{T}_{0}$, the $\mathrm{DF}$ becomes 50 or greater.

The inlet portion of the packed bed has the highest concentration, and breakthrough commences as the adsorption progresses. However, if the contact time to the outlet of the packed bed is set to be $T_{0}$, the non-dimensional concentration will immediately exceed 0.02 when breakthrough begins, and the DF will become less than 50. On the other hand, if the contact time to the outlet of the packed bed is set to be $T_{1}$, the non-dimensional outlet concentration has a margin of safety between it and the allowable value of 0.02 . As breakthrough begins, the time the gas passes through the breakthrough packed bed becomes invalid as the contact time, so the curve in this figure shifts to the right. It is thought that DF will become less than 50 when the 


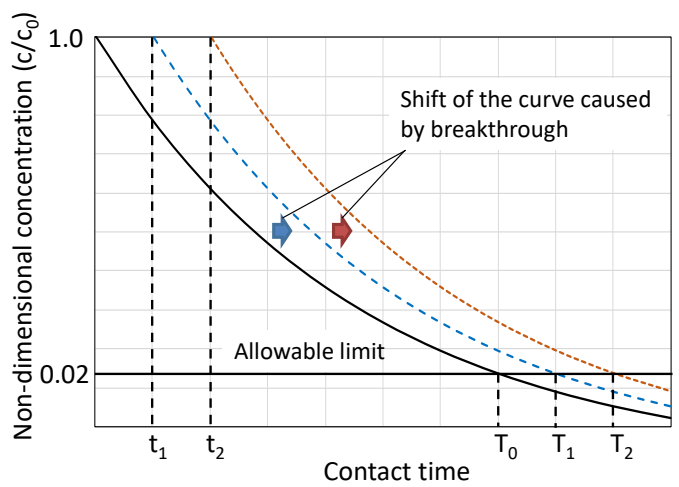

Figure 10 Typical relationship between contact time and concentration of methyl iodide in a plug flow of gas through packed silver zeolite bed. The conditions of test cases A-1 to A-4 are listed in Table 3.

breakthrough eventually progresses and reaches the state of the dashed line. In addition, when considering a mixing flow in the flow direction, instead of a plug flow, although the slope of the curve in Figure 10 becomes moderate due to the effect, the qualitative tendency is presumed to be similar.

When considering such a model, if the setting of the contact time to the outlet of the packed bed is increased from $T_{1}$ to $T_{2}$, the shiftable amount of the curve will increase, as shown in the figure, and the tolerance of invalid contact time when the gas passes through the breakthrough packed bed extends from $t_{1}$ to $t_{2}$. That is, the allowable thickness of the breakthrough packed bed increases. Accordingly, the allowable adsorption load increases by that increased thickness, but the increased amount is proportional to the length of the contact time that exceeds $\mathrm{T}_{0}$. However, in this model, it was assumed that the reaction speed constant $\mathrm{k}$ was constant downstream of the breakthrough packed bed, but in reality, silver ions, which contribute to the adsorption, are consumed by the reaction in this region, so k decreases. The slope of the curve in Figure 10 tends to moderate, especially at the position close to the breakthrough packed bed. In this case, $t_{1}$ and $t_{2}$ are smaller than the positions shown in the figure, and the proportional relationship no longer exists, but the qualitative tendency that the allowable adsorption load increases with the time exceeding $T_{o}$ is maintained. The allowable adsorption load shown in Figure 9 increases almost linearly, depending on the contact time, and demonstrates a tendency consistent with the considerations here, at least within the range of these test conditions.

On the other hand, even if the inlet concentration of methyl iodide increases, the shape of the curve does not change because the concentration is made non-dimensional by the inlet concentration, as shown in Figure 10. However, it is thought that consumption of silver ions, which can contribute to adsorption, also proceeds faster as the concentration increases. In the comparison between test A-1 and test A-2, the time for which DF can secure a value of 50 or greater in the case of A - 2, which is about double in concentration, has been almost halved, and the amount of absorbed methyl iodide is approximately equal.

In test A-3, although the conditions of temperature and pressure are different, the allowable adsorption load is in a linear relationship with the contact time indicated by the result of other test conditions, as shown in Figure 9, and the difference in contact time appears to be dominant over the adsorption load. Generally, it is predicted that the change in the temperature and in other conditions will affect reaction speed and diffusion. However, within the scope of this test condition, it is considered that these influences are not as pronounced as those of the contact time. 
Although the above discussion is based on an assumed plug flow, if we assume a different ideal flow, namely perfect mixing, the outcome is considered to be as follows. In perfect mixing, the concentration $\mathrm{c}$ in the packed bed is equal to the outlet concentration $\mathrm{c}_{\mathrm{ex}}$. Based on the material balance principle, the relationship with the inlet concentration $c_{o}$ is expressed by equation (7)

$$
\mathrm{c}=c_{e x}=c_{\mathrm{o}}-k T c_{e x}
$$

where, $\mathrm{T}$ is the average residence time of the gas in the packed bed, that is, the contact time. However, $\mathrm{t}$ in equation (6) is the contact time until position $\mathrm{z}$ is reached in the packed bed, but since it is a perfect mixing flow, $\mathrm{T}$ in equation (7) is not the contact time corresponding to the position. Based on equation (7), DF is expressed by equation (8).

$$
\mathrm{DF}=c_{0} / c_{e x}=1+k T
$$

Therefore, to reach a certain DF, the longer the contact time is, the lower the reaction speed may be. On the other hand, it is thought that the decline in the reaction speed is caused by the sequential progression of silver ions from the reactive surface of silver zeolite particles toward their interior. Therefore, if a low reaction speed is allowed, the allowable consumption of silver ions will increase accordingly, that is, the allowable adsorption load will increase.

On the other hand, when the zeolite is removed after the adsorption test, zeolite particles that have reacted with iodine and turned yellow are observed, and also zeolite particles that are still white. Therefore, it is not a perfect mixing flow in the packed bed but rather in an intermediate state of the ideal plug flow, and it is considered that the mechanism related to the adsorption capacity discussed above also coexists.

(3) Performance when the difference between gas temperature and dew-point is small

The basic performance under the conditions assumed for the actual device was confirmed by the test in III-1-(2). To confirm the design margin, a test was conducted for the case in which the difference between the gas temperature and the dew point is small, and the effect was determined.

Based on test A-4, the test condition was set with a reduced superheating degree of steam for test A-5. The conditions are described in Table 4 in comparison with the conditions of test A-4. The changes in inlet concentration, outlet concentration, and methyl iodide removal rate in test A-5 are shown in Figure 11. The period for which DF maintains the design target of 50

Table 4 Test cases for methyl iodide adsorption of silver zeolite to clarify the effects of

\begin{tabular}{|c|c|c|}
\hline Test number & A-4 (Reference) & $\mathrm{A}-5$ \\
\hline Contact time $(s)$ & 0.134 & 0.137 \\
\hline Methyl iodide concentration (vol ppm) & 57 & 46 \\
\hline Difference between gas temperature and dew point (K) & 12.5 & 4.6 \\
\hline Gas pressure ( $\mathrm{kPa}$ [gage]) & 250.4 & 249.9 \\
\hline Gas composition other than methyl iodide & Steam $100 \%$ & Steam $100 \%$ \\
\hline Temperature of silver zeolite before testing & $\begin{array}{l}\text { Preheated to the gas } \\
\text { temperature }\end{array}$ & $\begin{array}{l}\text { Preheated to the gas } \\
\text { temperature }\end{array}$ \\
\hline Absorbed methyl iodide before DF becomes less than 50 (mg) & 1,985 & 788 \\
\hline Ratio of silver reacted with iodide (\%) & 7.4 & 2.9 \\
\hline $\begin{array}{l}\text { Evaluated allowable load of methyl iodide on two organic iodine filters for a } \\
\text { plant }(\mathrm{kg})\end{array}$ & 158.6 & 63.0 \\
\hline
\end{tabular}
superheating level 


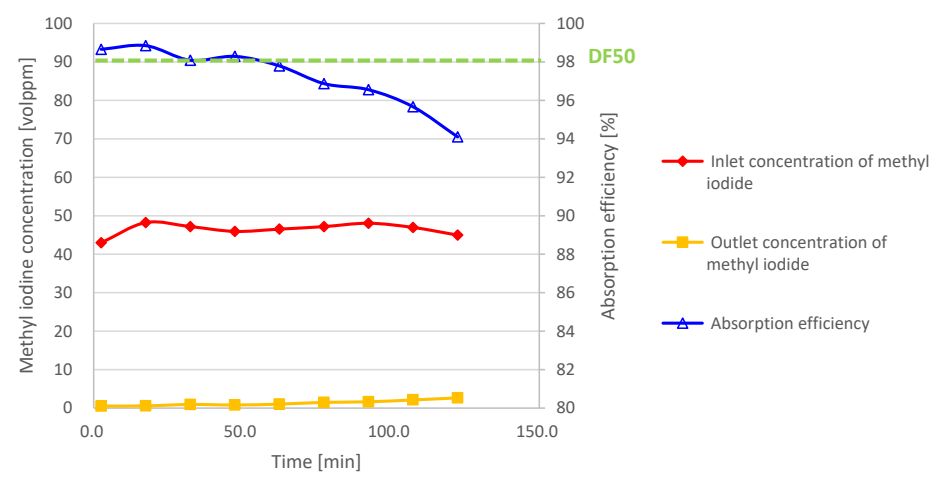

Figure 11 Results of methyl iodide adsorption performance test A-5 Test conditions are listed in Table 4 as test number A-5.

or greater in this test, the proportion of silver that absorbed iodine during that period, and the calculated result of the allowable adsorption load of the organic iodine filter are also described in Table 4. Each value is smaller than that in the test that A-4 is to be compared with, and it is understood that the decrease in the difference between gas temperature and dew-point affects the adsorption performance. However, it was confirmed that the required adsorption performance was maintained even under these conditions.

\section{(4) Confirmation of adsorption state stability}

Next, to check the adsorption state stability, we heated the absorbed silver zeolite to see whether iodine would be desorbed. In this test, the silver zeolite after the A-3 test shown in Table 3 was used as a sample. While the DF of this silver zeolite was maintained at 50 or greater, with the total amount of methyl iodide absorbed by the $50 \mathrm{~g}$ of silver zeolite packed in the test column being shown in Table 3, the total amount that remained by the end of the test was $3,678 \mathrm{mg}$. A total of $2.5 \mathrm{~g}$ of silver zeolite, which can be confirmed to turn yellow by visual check, was collected from the particles of silver zeolite removed from this test column and placed in the reaction vessel of the apparatus shown in Figure 12. If methyl iodide was uniformly absorbed by silver zeolite, $184 \mathrm{mg}$ of methyl iodide would be absorbed in this sample of $2.5 \mathrm{~g}$, but because the degree of yellow coloration varied from zeolite to zeolite, those more intensely colored were selected for the sample. Therefore, at least $184 \mathrm{mg}$ of methyl iodide, which is the average value, was thought to be absorbed in this sample.

Next, the sample temperature was raised to $100^{\circ} \mathrm{C}$ and maintained for 30 minutes while hydrogen gas flowed in. Thereafter, the temperature was raised in increments of $100^{\circ} \mathrm{C}$ and maintained for 30 minutes each time. Gas that passed through the reaction vessel was sampled from sampling port 1 with a micro syringe, and the methyl iodide concentration was measured with GC-FID. Also, gas capture was conducted by pure water in sampling port 2 and by sodium thiosulfate solution in sampling port 3, and iodine ion analysis was carried out by ion chromatography (IC: Nippon Dionex ICS-2000, lower limit of detection concentration was $0.2 \mathrm{mg} / \mathrm{L}$ ). Furthermore, the entire flow of gas was captured from sampling port 4, and the concentration of $\mathrm{I}_{2}$ was analyzed with a detection tube $(9 \mathrm{~L}$, made by GASTEC, lower limit of concentration detection: $0.2 \mathrm{vol} \mathrm{ppm}$ ).

In this test, methyl iodide was detected in the gas collected from port 1, in the process of heating the silver zeolite sample to $300-400^{\circ} \mathrm{C}$. The total amount of methyl iodide calculated 


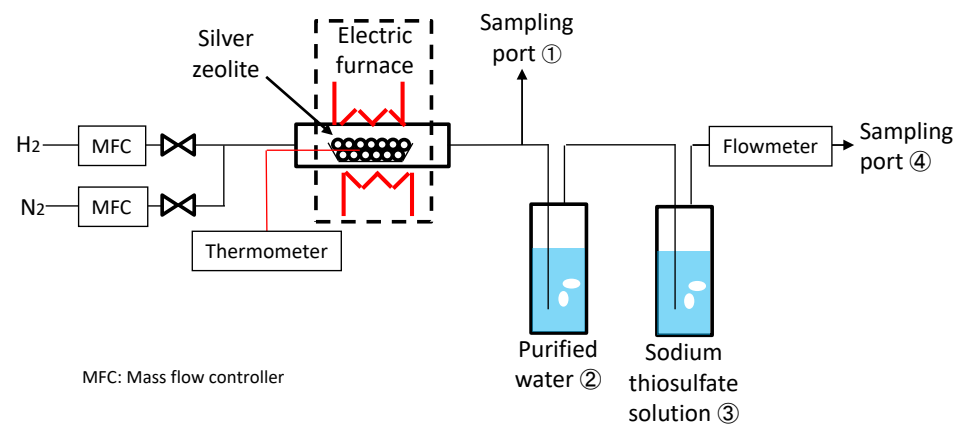

Figure 12 The test facility for iodide desorption from the silver zeolite

from that concentration was $0.04 \mathrm{mg}$. It was thought that this methyl iodide did not chemically react with silver ions and was physically absorbed by the zeolite, but the amount was as small as $0.02 \%$ of $184 \mathrm{mg}$, which is the total amount of methyl iodide absorbed by this sample. Therefore, it is considered that most of the iodine absorbed by silver zeolite chemically reacts with silver and is stably retained. Methyl iodide, which was released by heating, transfers into the gas, but in the case of the actual device, it is considered that recombination will occur when it flows through the silver-zeolite-packed bed, and the problem of re-emission will not arise in practice.

On the other hand, from the ion analysis of pure water, $\mathrm{I}^{-}$was detected when the silver zeolite temperature was $400^{\circ} \mathrm{C}$ or higher. If the $\mathrm{I}^{-}$came from methyl iodide, the total amount of $\mathrm{I}^{-}$would correspond to $10.3 \mathrm{mg}$ of methyl iodide, meaning that $5.6 \%$ of the total absorbed amount was desorbed. Furthermore, from the sodium thiosulfate solution, $\mathrm{I}^{-}$corresponding to $1.0 \mathrm{mg}$ of methyl iodide was detected. $\mathrm{I}_{2}$ was detected from the gasbag, and the total amount was $0.07 \mathrm{mg}$. The total of these is greater than the total amount estimated from the methyl iodide concentration detected at port 1 , and it is considered that silver iodide was reduced by heating in a hydrogen atmosphere, and desorbed iodine was detected.

As shown in Figure 3, there is an FCVS filter device upstream of the organic iodine filter. Fission products are collected in the scrubber. When radiolysis of water occurs, hydrogen is generated and may flow into the organic iodine filter. However, this filter device is designed in such a manner as to discharge the scrubber water into the containment vessel, in which case, it is refilled with fresh water. Therefore, operation management is necessary to suppress the generation of hydrogen by replacing scrubber water at an appropriate time, sending nitrogen gas to the organic iodine filter to lower the hydrogen concentration, and cooling down the silver zeolite during the period before water replacement.

\section{(5) Performance confirmation under initial venting conditions}

In the initial stage of venting, the iodine adsorption performance of silver zeolite may deteriorate due to the influence of hydrogen contained in the venting gas and the condensation of steam on the surface of the silver zeolite. Therefore, the test was carried out under the conditions in Table 5, and the performance under transient conditions from the start of the vent to the steady state was confirmed. Of the two test conditions, B-1 reproduces the gas composition in the containment vessel at the start of the venting, as obtained from the MAAP analysis. The vapor of this composition will flow into the FCVS system, as the scrubber water temperature is low in the FCVS filter device, which is upstream of the organic iodine filter. As the steam condenses while passing through the scrubber, a high concentration of hydrogen may flow into the organic iodine filter. Therefore, another test condition, B-2, was set, assuming that the steam 
Table 5 Test cases for methyl iodide adsorption of silver zeolite, simulating vent startup conditions

\begin{tabular}{|c|c|c|}
\hline Test number & $\mathrm{B}-1$ & B-2 \\
\hline Contact time $(\mathrm{s})$ & 0.173 & 0.166 \\
\hline Methyl iodide concentration ( vol ppm) & 126 & 120 \\
\hline Gas temperature $\left({ }^{\circ} \mathrm{C}\right)$ & 101 & 101 \\
\hline Gas pressure ( $\mathrm{kPa}$ [gage]) & 15.9 & 10.2 \\
\hline Gas composition other than methyl iodide & $\begin{array}{c}\text { Steam } 10 \% \\
\text { Hydrogen } 30 \% \\
\text { Nitrogen } 60 \%\end{array}$ & $\begin{array}{c}\text { Hydrogen } 33 \% \\
\text { Nitrogen } 67 \%\end{array}$ \\
\hline Temperature of silver zeolite before testing & Room temperature & Room temperature \\
\hline Absorbed methyl iodide before DF becomes less than $50(\mathrm{mg})$ & 479 & 1,109 \\
\hline Ratio of silver reacted with iodide (\%) & 1.8 & 4.1 \\
\hline Evaluated allowable load of methyl iodide on two organic iodine filters for a plant $(\mathrm{kg})$ & 38.3 & 88.7 \\
\hline
\end{tabular}

DF : Decontamination Factor.

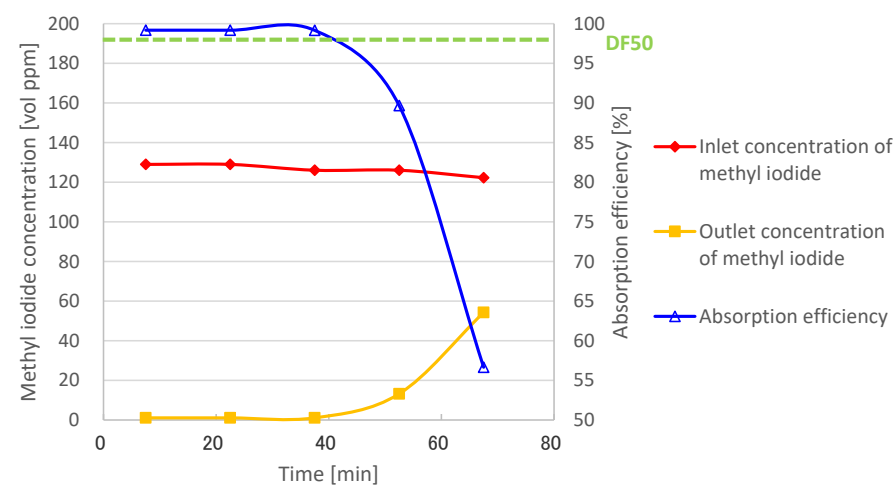

Figure 13 Results of methyl iodide adsorption performance test B-1 Test conditions are listed in Table 5 as test number B-1.

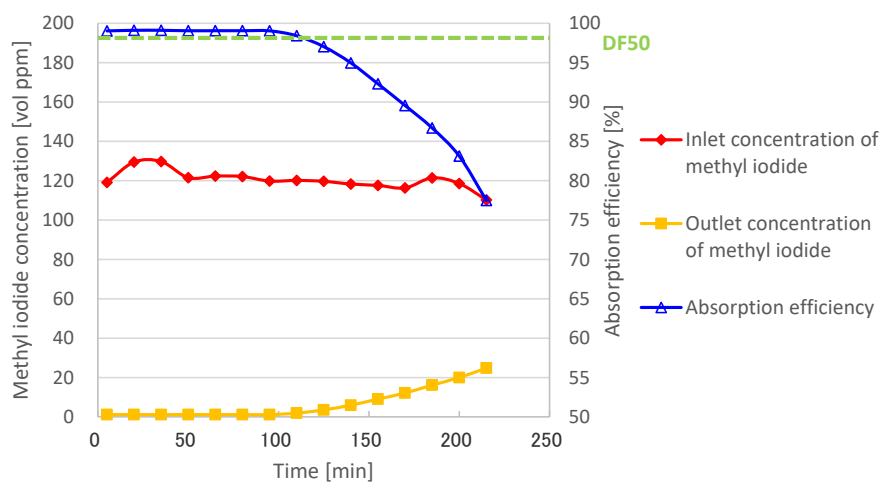

Figure 14 Results of methyl iodide adsorption performance test B-2 Test conditions are listed in Table 5 as test number B-2.

completely condensed in the scrubber at the very beginning of the venting.

Change of inlet concentration, outlet concentration and methyl iodide removal rate from the start of each test under each condition is shown in Figure 13 and Figure 14. In Table 5, the period during which DF maintains the design target of 50 or greater under each test condition, the fraction of silver, which absorbs iodine during that period, and the calculated result of the allowable adsorption load of the organic iodine filter are also described. All values are significantly lower 
than those in the steady state shown in Table 3, but a DF of 50 or greater is obtained, and the allowable adsorption load of the organic iodine filter also exceeds the organic iodine of about $1.3 \mathrm{~kg}$ actually generated in the containment vessel. It was confirmed that the organic iodine filter has sufficient effectiveness even in the transient state at the beginning of the venting.

\section{(6) Performance at restart after temporary suspension of venting}

Although it was confirmed by the previous test that the silver zeolite provides the necessary performance even at the beginning of the venting, it was found that the vapor condensation at the beginning of the venting affects the adsorption performance. However, in the first venting after the accident, as shown in Table 2, most of the gas flowing is nitrogen and hydrogen, and water vapor is about $10 \%$. The silver zeolite is dry in the initial state, and the effect of vapor condensation was considered to be limited, according to the previous test that simulated this condition.

However, a different situation may result if the venting is temporarily stopped for some reason and resumed, with vapor condensed at the time of stoppage and the silver zeolite dampened, which is different from the condition of the test described in the preceding paragraph in which venting is started when silver zeolite is dry. Therefore, a test was conducted to wet the silver zeolite and then check the performance by flowing the gas at room temperature. Steam not containing methyl iodide was flowed into the test column of the test facility in Figure 4. After the temperature and pressure reached steady state, the flow of steam was stopped. Then the heat was allowed to dissipate spontaneously to wet the silver zeolite with condensed vapor in the test column. After confirming that the test column had reached room temperature, steam containing methyl iodide was flowed into the test column, and the change in concentration was measured. In addition, because the main component of the gas is water vapor in the second and subsequent venting(s) after the accident, hydrogen and nitrogen were not mixed in this test.

The test conditions are shown in Table 6. Test C-1 used almost the same test conditions as test A-3, except that room temperature wet silver zeolite was specified as an initial condition.

The test result is shown in Figure 15. It is thought that the low adsorption performance at the beginning is due to the wet silver zeolite. After that, the adsorption performance increased with time, and about 40 minutes from the start of venting the DF exceeded 50 and demonstrated stable performance. This is thought to be due to the evaporation of the condensed water adhered to the silver zeolite by the flow of superheated steam.

Next, we checked the limit condition for maintaining the performance by decreasing the gas flow velocity in the test. As for the second and subsequent venting(s), it is not always necessary to wait until the pressure of the containment vessel reaches $2 \mathrm{Pd}$ as in the first venting, and since the decay heat of the core also decreases, it is not a necessity to apply the first venting

Table 6 Test conditions for methyl iodide adsorption of silver zeolite simulating vent restart conditions

\begin{tabular}{|c|c|c|}
\hline Test number & $\mathrm{C}-1$ & $\mathrm{C}-2$ \\
\hline Contact time (s) & 0.152 & 0.388 \\
\hline $\begin{array}{l}\text { Methyl iodide concentration } \\
(\text { vol ppm) }\end{array}$ & 56 & 46 \\
\hline $\begin{array}{l}\text { Difference between gas tem- } \\
\text { perature and dew point }(K)\end{array}$ & 8.4 & 8.3 \\
\hline Gas pressure (kPa [gage]) & 5.6 & 8.2 \\
\hline $\begin{array}{l}\text { Gas composition other than } \\
\text { methyl iodide }\end{array}$ & Steam 100\% & Steam $100 \%$ \\
\hline $\begin{array}{l}\text { Temperature of silver zeolite } \\
\text { before testing }\end{array}$ & $\begin{array}{l}\text { Room } \\
\text { temperature }\end{array}$ & $\begin{array}{l}\text { Room } \\
\text { temperature }\end{array}$ \\
\hline
\end{tabular}




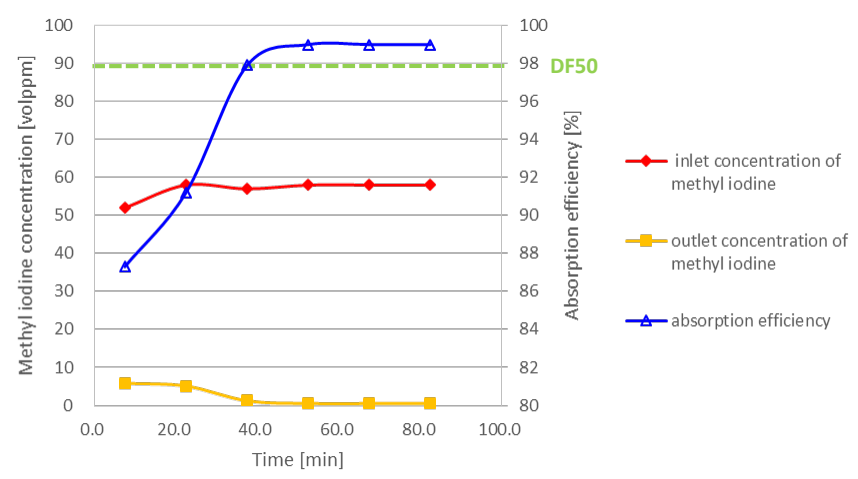

Figure 15 Results of methyl iodide adsorption performance test $\mathrm{C}-1$ Test conditions are listed in Table 6 as test number $\mathrm{C}-1$.

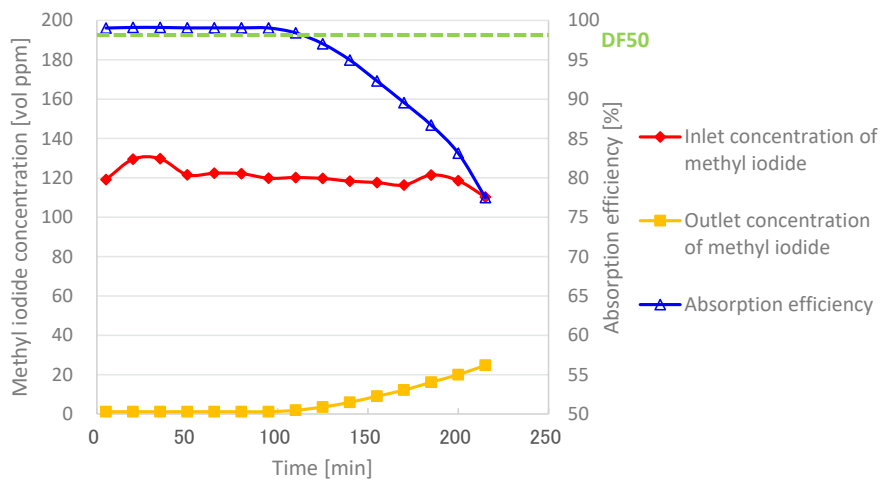

Figure 16 Results of methyl iodide adsorption performance test C-2 Test conditions are listed in Table 6 as test number $\mathrm{C}-2$.

starting condition. As a result, it was found that the target performance can almost be satisfied continuously from the start of venting, as shown in Figure 16, by reducing the gas flow rate up to the condition of test $\mathrm{C}-2$ and lengthening the contact time.

\section{(7) Discussion on operation management of the organic iodine filter}

The test results in III-1-(5) showed that the silver zeolite should be in a dry state in the initial stage of the venting. Therefore, management is necessary to keep the interior of the iodine filter dry when it is in standby. For this reason, it was decided that operation management should be conducted to isolate the front and rear of the filter, which is in a standby state with a rupture disk at a low-pressure setting. The inside of the filter is filled with nitrogen gas and kept in a dry state. In addition, the silver zeolite is removed from the inside of the iodine filter from time to time to check its condition.

Also, from the test result in III-1-(6), it was found that if venting is temporarily stopped, water vapor condenses due to heat dissipation, the silver zeolite becomes wet, and the adsorption performance is affected when venting restarts. However, for the venting of the containment vessel, since the atmosphere is expected to act as a heat sink and cool the containment vessel, venting should be continued until the containment vessel is able to resume cooling, and venting becomes unnecessary. Therefore, suspending venting and restarting it is not a good idea. However, when the venting is temporarily stopped for some reason, it is desirable to trigger an operation 
procedure, namely narrowing the opening of the adjustment valve of the vent system at the time of the venting restart, before the gas starts to flow, so that the desired performance level of the organic iodine filter is continuously secured. However, prevention of containment vessel breakage due to pressure rise takes priority, even in this case, while monitoring the tendency of the containment vessel pressure, so the opening of the valve is narrowed when the pressure decreases as a result of the venting. The findings of this study indicate that it is not necessary to fully open the valve at the time of the venting restart, so an operation based on pressure monitoring is beneficial.

Furthermore, it was found from the adsorption stability verification test of III-1-(3) that several percent of absorbed iodine may be desorbed if silver iodide is reduced by hydrogen after venting. It is important to flow the nitrogen gas to the organic iodine filter after venting, discharge the scrubber water of the upstream FCVS filter device to the containment vessel, fill in fresh water and suppress the generation of hydrogen by radiolysis of water.

\section{Filter Unit Test}

\section{(1) Outline of test facility}

It was confirmed by the previous tests that the packed bed of silver zeolite can produce a DF of 50 or greater by ensuring adequate contact time. However, since the flow velocity of the gas passing through the candle-type filter unit may not necessarily be uniform, we conducted a test using a candle-type filter unit with the same size as the actual device, and determined the distribution of the passing flow velocity. We also examined the relationship between the passing flow rate in the candle-type filter unit and the pressure loss, using the characteristics thereof to evaluate the flow rate deviation between the candle-type filter units by numerical analysis.

The outline of the test facility is shown in Figure 17. Candle-type filter units of the same size as the actual device are installed in the test chamber. Steam generated by the boiler is supplied from the upper part of the chamber like the actual organic iodine filter. It passes through the candle-type filter unit from the outside to the inside, then is discharged from the lower part of the chamber to outside the system. The amount of steam to be supplied can be set to the maximum steam flow rate per candle-type filter unit, as the actual device is designed for. An anemometer (0965-04 made by Kanomax Japan Inc) is inserted inside the candle-type filter

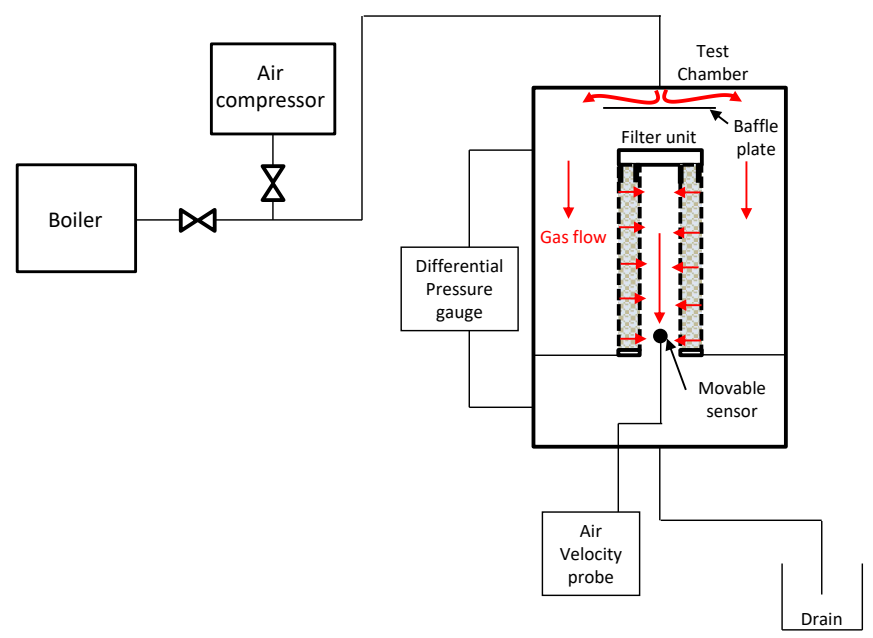

Figure 17 The filter unit test facility 
unit to measure the flow velocity by moving up and down along the central axis.

This makes it possible to track the distribution of the velocity of the steam flowing downward in the candle-type filter unit inner cylinder, after passing through the silver-zeolite-packed bed in the candle-type filter unit. When using this anemometer, we changed the steam generation rate of the boiler, confirmed that the calculated steam flow velocity value and the measured value were in a linear relationship, and judged this to be effective for the purpose of determining the relative velocity distribution within this test range.

\section{(2) Test result and evaluation}

Measurement of the gas velocity distribution when the steam flowed with the maximum steam flow rate per candle-type filter unit is shown in Figure 18. The vertical axis in this figure shows the non-dimensional flow velocity, using the flow velocity at the outlet of the candle-type filter unit as the reference. A lower position in the inner cylinder of the candle-type filter unit corresponds to a higher gas velocity, which changes almost linearly according to the height. That is, the velocity of the gas that passes through the packed bed in the inner cylinder of the candle-type filter unit increases linearly towards the outlet in the lower portion of the cylinder while being nearly uniformly added, and the flow rate of the gas that passes through the silver-zeolite-packed bed of the candle-type filter unit from the outside to the inside is almost uniform in the unit, regardless of the height.

Furthermore, since 19 candle-type filter units are installed in one filter vessel in the actual device, we evaluated the flow distribution by three-dimensional flow analysis using the general-purpose analysis code STAR-CCM+. STAR-CCM+, including its predecessor STAR-CD, is a general-purpose code that is widely used in flow analysis.

In this analysis, since the Mach number of the filter vessel inlet piping is about 0.2 at the maximum, the pressure change in the inlet piping and the filter vessel is about $5 \%$, and the concentration change is small, so the mass conservation equation and the momentum conservation equation are treated as an uncompressed steady flow. Also, the turbulence model is RANS type (Realizable k- $\varepsilon$ (two-layer type)), in which the handling of wall effects is based on the Ally+ model, which is a hybrid of a low-Reynolds-type model and a high-Reynolds-type model.

The model comprises one filter vessel and its inlet/outlet piping. From the results of the candle-type filter unit test, the correlation was obtained between the calculated value of the average velocity of the gas passing through the silver-zeolite-packed bed and the pressure loss. Giving this characteristics to the porous media by setting pressure loss coefficient per unit length, the candle-type filter unit was modeled. The analysis mesh is shown in Figure 19. We adopted a polyhedral cell, which is considered to be in good conformity with the shape and of generally

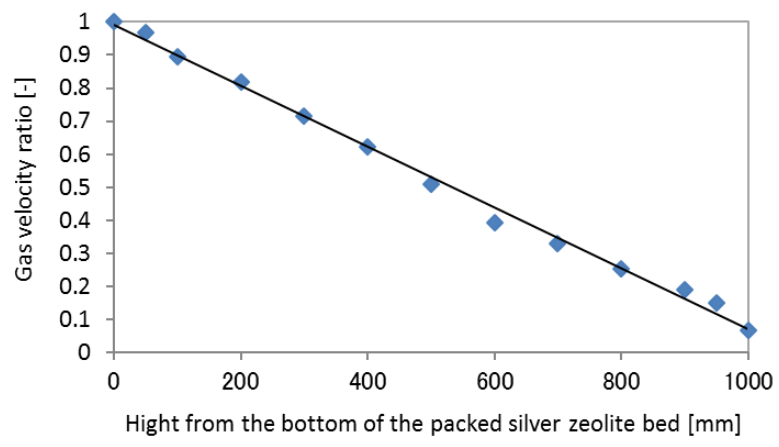

Figure 18 Gas velocity distribution along the centerline of a filter unit 
high calculation convergence and stability. Furthermore, prism cells in the form of thin plates were arranged in the vicinity of the wall surface to obtain the appropriate wall shear force. As for the boundary conditions, the velocity is given for the inlet pipe, and the pressure condition is given for the outlet pipe. As the composition of the venting gas is mostly water vapor, except during a short period of time immediately after the initiation of venting, the fluid is treated as approximately $100 \%$ water vapor and assigned the physical properties thereof.

The flow velocity distribution on the longitudinal cross section in the center of the filter vessel is shown in Figure 20, from analysis of the maximum flow rate of the actual device for one filter vessel (fluid: water vapor, volumetric flow rate: $8 \mathrm{~m}^{3} / \mathrm{s} / \mathrm{unit}$, mass flow rate: $7.9 \mathrm{~kg} / \mathrm{s} / \mathrm{unit}$ ). Gas introduced from the upper nozzle of the vessel is bent in the direction of the wall surface of the vessel by the baffle plate right under the nozzle, and turns into a complicated flow in the space above the candle-type filter unit. However, the gas flows almost uniformly into each

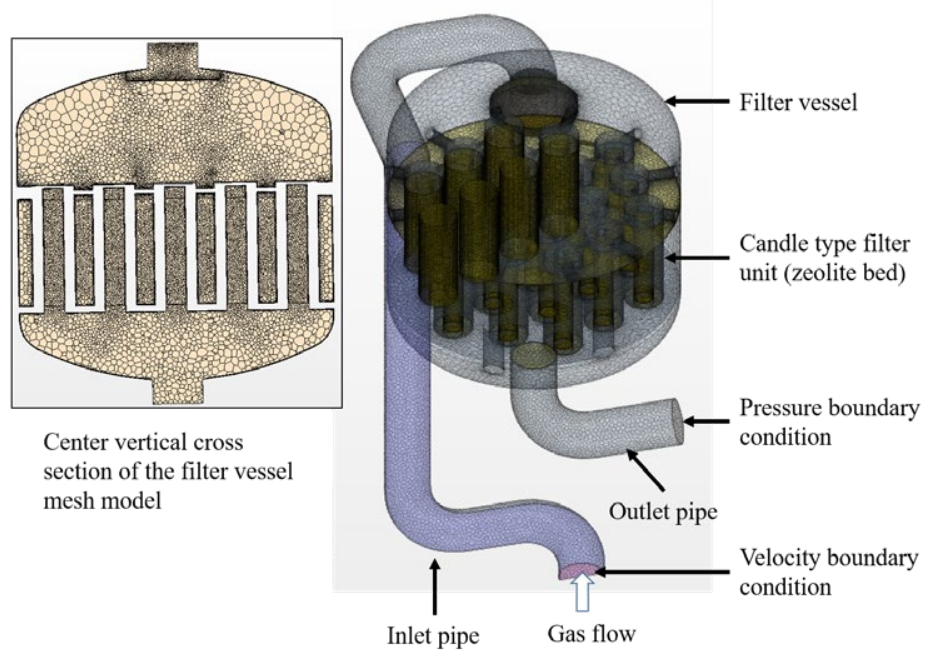

Figure 19 An analysis mesh for the organic iodine filter and its inlet and outlet pipes

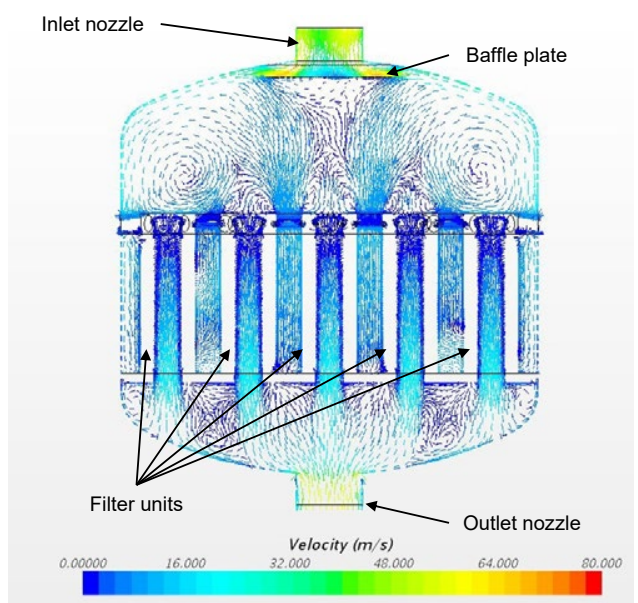

Figure 20 A numerical analysis result showing gas velocity distribution in the center cross-section of the organic iodine filter 
candle-type filter unit, and the flow velocity distribution inside the candle-type filter unit exhibits almost the same tendency among all the units. The flow rate in each candle-type filter unit and the deviation from the average value is shown in Table 7. The variation in the flow rate is within $\pm 1.0 \%$. Figure 21 shows the velocity distribution in the vertical direction of the gas passing through the packed bed in each candle-type filter unit. The variation is $\pm 11 \%$.

To provide a margin based on this result, we set the velocity variation for the gas passing through the packed bed to $15 \%$ in our design. When venting of the containment vessel is

Table 7 Numerical analysis result showing flow distribution among the filter units at the maximum venting flow conditions

\begin{tabular}{ccc}
\hline $\begin{array}{c}\text { Filter unit } \\
\text { identification number }^{\mathrm{a})}\end{array}$ & $\begin{array}{c}\text { Mass flow } \\
(\mathrm{kg} / \mathrm{s})\end{array}$ & $\begin{array}{c}\text { Deviation from the } \\
\text { average }(\%)\end{array}$ \\
\hline 11 & 0.411 & 0.4 \\
12 & 0.411 & 0.4 \\
13 & 0.412 & 0.7 \\
21 & 0.407 & -0.6 \\
22 & 0.409 & -0.2 \\
23 & 0.411 & 0.3 \\
24 & 0.409 & -0.1 \\
31 & 0.408 & -0.5 \\
32 & 0.408 & -0.5 \\
33 & 0.411 & 0.4 \\
34 & 0.409 & -0.2 \\
35 & 0.408 & -0.4 \\
41 & 0.409 & -0.2 \\
42 & 0.411 & 0.3 \\
43 & 0.410 & 0.1 \\
44 & 0.406 & -0.8 \\
51 & 0.411 & 0.4 \\
52 & 0.411 & 0.3 \\
53 & 0.411 & 0.3 \\
\hline
\end{tabular}

a) Locations and identification numbers of filter units are shown in Fig. 2.
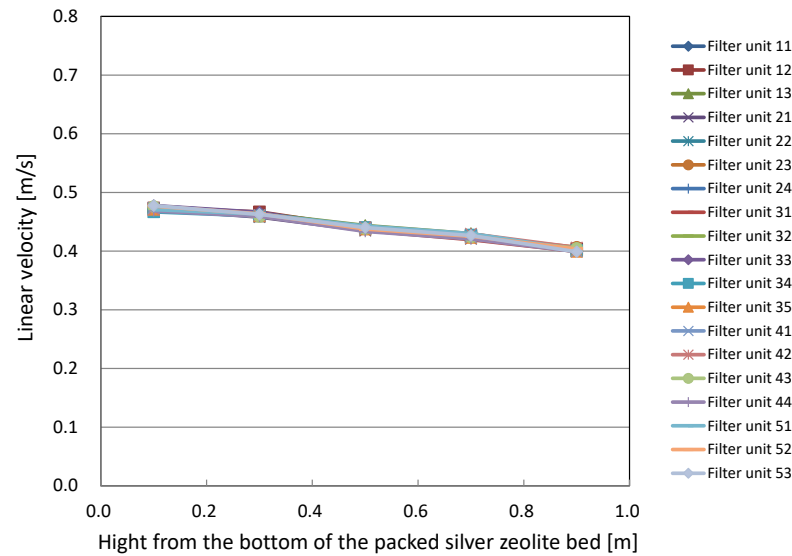

Figure 21 Numerical analysis results of the distribution of linear velocity of the gas passing through packed silver zeolite bed in candle type filter units at the maximum venting flow conditions 
performed when the containment vessel reaches twice the maximum working pressure, defined as the pressure limit in the case of an accident, the contact time of the gas in the silver zeolite packed bed in the organic iodine filter is 0.222 seconds, as shown in Table 2 . It is necessary to ensure the required adsorption performance with a contact time of 0.188 seconds because of the $15 \%$ velocity variation in our design. In the adsorption performance tests shown in Table 3 and Table 5, it has been confirmed that the DF is 50 or greater, and the allowable adsorption load is adequate, though in all cases, the target performance is achieved with a contact time less than 0.188 seconds. Therefore, it is thought that adequate performance can be secured even though there is velocity variation in the filter.

\section{Conclusions}

The development of an FCVS and introduction of the actual device are underway to protect the containment vessel from over-pressure damage as well as to considerably reduce the emission of radioactive substances at the time of severe accidents at nuclear power plants. In this study, to curb the emission of organic iodine into the environment, since it cannot be captured by a scrubber or a metal filter, we have developed a filter using silver zeolite as an absorbent, which is $13 \mathrm{X}$ crystalline zeolite as its basic skeleton with sodium ions in the aluminosilicate skeleton exchanged with the silver ions.

In the organic iodine adsorption test, we simulated the venting gas composition and vapor conditions at the time of venting of the containment vessel and measured the DF for methyl iodide. The result showed that an adsorption performance with a DF of 50 or greater is ensured by appropriately setting the contact time in the silver-zeolite-packed bed.

Also, it was found that although the allowable adsorption load declines due to condensation of steam or the presence of hydrogen at the start of venting, the DF can be kept at 50 or greater by maintaining the silver zeolite in a dry state during standby.

The findings obtained from these tests were reflected in the operation management of the venting. First, it is important to keep the inside of the filter dry during standby. It was also found that when the silver zeolite is wet after venting commences, the performance will temporarily deteriorate until it is dried again, which is reflected in the operation strategy of venting to secure a stable DF. Furthermore, it was found that when hydrogen flows into the silver-zeolite-packed bed after iodine adsorption, several percent of the absorbed iodine may be desorbed. Therefore, measures are taken in the operation management to replace the scrubber water of the FCVS filter device installed upstream at an appropriate time, and to suppress the generation of hydrogen by radiolysis of the water.

In the filter unit test, we determined the velocity distribution of the gas passing through the packed bed using a unit with the same structure and size as those of the actual device, performed flow analysis in the filter vessel, and confirmed that the contact time of the gas passing through the silver-zeolite-packed bed is longer than the contact time for which the required performance was confirmed in the organic iodine adsorption test. Based on the above, the filter developed in this study was evaluated to have a DF of 50 or greater for organic iodine. This organic iodine filter is being introduced to the unit $6 \& 7$ reactors at the Kashiwazaki Kariwa Nuclear Power Station.

We would like to express our deepest gratitude to Ms. Yoko Umeda of TEPCO Research Institute for her valuable advice in this study, and Mr. Toru Ida and Mr. Takashi Tachikawa of Kobelco Research Institute Inc. for their collaboration in the tests. 


\section{References}

1) S. Kawamura, S. Omori, T. Kimura, T. Takiguchi, T. Narabayashi, "A comprehensive approach to reducing radioactive material release in BWR containment venting," Proc. 20th Natl. Symp. on Power and Energy Systems, Sendai, Japan, Jun. 18-19, 2015 (2015). [in Japanese]

2) T. Narabayashi, S. Kawamura, "Development of high efficiency filtered containment venting system by using AgX," Proc. 20th Natl. Symp. on Power and Energy Systems, Sendai, Japan, Jun. 18-19, 2015 (2015). [in Japanese]

3) S. Kawamura, T. Kimura, "Filtered venting system no kaihatsu to Kashiwazaki Kariwa unit 6, 7 heno tekiyou," Energy Rev., 2014[11], 20-24 (2014). [in Japanese]

4) S. Kawamura, T. Kimura, S. Omori, T. Narabayashi, "Development of a filtered containment venting system for nuclear power plants," Trans. At. Energy Soc. Jpn, J14.036, Advance publication by J-Stage (2015). [in Japanese]

5) Tokyo Electric Power Company, Fukushima Nuclear Accident Analysis Report (2012).

6) T. Kanai, M. Furuya, T. Arai, Y. Nishi, K. Shirakawa, N. Tanaka, "Sophistication of filtered containment venting system operation,(5) Decontamination performance of iodine," Proc. 2015 Annu Meeting of AESJ, 20th Natl. Symp. on Power and Energy Systems, Hitachi, Japan, Mar. 20-22, 2015 (2015). in Japanese]

7) T. Ishii, N. Sato, A. Kirishima, D. Akiyama, T. Narabayashi, "Sorption of radioactive methyl iodide by silver doped zeolite for filtered venting system," Proc. 20th Natl. Symp. on Power and Energy Systems, Sendai, Japan, Jun. 18-19, 2015 (2015). [in Japanese]

8) T. Narabayashi, T. Aida, T. Kanai, T. Konno, S. Ito, "Robustization of high efficiency filtered containment venting system by using AgX," Proc. 20th Natl. Symp. on Power and Energy Systems, Sendai, Japan, Jun. 18-19, 2015 (2015). [in Japanese]

9) T. Kobayashi, J. Wang, Y. Uzuyama, K. Endo, "Application of AgX radioiodine adsorbent as severe accident countermeasures," Proc. 20th Natl. Symp. on Power and Energy Systems, Sendai, Japan, Jun. 18-19, 2015 (2015). [in Japanese]

10) OECD/NEA/CSNI, Status Report on Filtered Containment Venting, NEA/CSNI/R (2014) 7 (2014).

11) Japan Society of Mechanical Engineers, Kikaikougakubinran Kaiteidai6ban, Tokyo (1977). [ in Japanese]

12) U. S. Nuclear Regulatory Commission, Methods and Assumptions for Evaluating Radiological Consequences of Design Basis Accidents at Light-water Nuclear Power Reactors, Regulatory Guide 1.195 (2003).

13) L. Soffer, S. Burson, C. Ferrell, R. Lee, J. Ridgely, Accident Source Terms for Light-water Nuclear Power Plants, U. S. Nuclear Regulatory Commission, NUREG-1465 (1995).

14) E. Beahm, C. Weber, T. Kress, G. Parker, Iodine Chemical Forms in LWR Severe Accidents, U. S. Nuclear Regulatory Commission, NUREG/CR-5732 (1992). 